\title{
Assessment of Genetic Diversity in Bread Wheat (Triticum aestivum L.) Genotypes
}

\author{
S.G.P. Karthikeya Reddy ${ }^{*}$, C.A. Babariya and M.H. Sapovadiya
}

Department of Genetics and Plant Breeding, College of Agriculture, Junagadh Agricultural University, Junagadh-362001, Gujarat, India

*Corresponding author

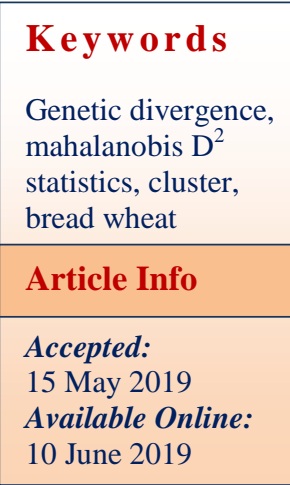

\section{Introduction}

Wheat (Triticum aestivum L.) is the second most important cereal crop of India after rice, occupies an area of 30.78 million hectares with the production and productivity of 98.51 million tons and $3200 \mathrm{~kg} / \mathrm{ha}$, respectively. In Gujarat wheat has 996 thousand hectares area, 2738 thousand tonnes production and 2750 $\mathrm{kg} / \mathrm{ha}$ productivity during 2016-17 (Anon., 2018). Availability of sufficient genetic variability is very important in a crop
An experiment with seventy genotypes of bread wheat carried out to study the nature and magnitude of divergence using Mahalanobis $\mathrm{D}^{2}$ statistics, in randomized block design with three replications. The data for twelve important quantitative traits were recorded from the genotypes raised. High genotypic and phenotypic coefficient of variation were observed for grain weight per main spike followed by biological yield per plant, grain yield per plant, 1000 grain weight, harvest index, number of productive tillers per plant and number of grains per main spike. High heritability coupled with high to moderate genetic advance expressed as per cent of mean were observed for grain weight per main spike, biological yield per plant, grain yield per plant, 1000 grain weight, harvest index, number of grains per main spike, number of productive tillers per plant and plant height. The seventy genotypes of bread wheat were grouped into five clusters using Tocher's method. The genotypes in cluster I and cluster V exhibited high degree of genetic diversity. The cluster IV had the highest mean values for number of grains per main spike; grain yield per plant and biological yield per plant grain yield per plant, grain weight per main spike, biological yield per plant, 1000 grain weight contributed maximum towards genetic divergence. 
basis of appropriate criteria. Mahalanobis $\mathrm{D}^{2}$ technique is one of the potent tools for measuring genetic divergence. In plant breeding, genetic diversity play an important role because hybrids between lines of diverse origin, generally, display greater heterosis than those between closely related parents and may generate broad spectrum of genetic variability in segregating populations (Arunachalam, 1981).To a plant breeder single character is of not much importance as the combined merit of number of desirable traits and it becomes more important when he/she is concerned with a complex trait like grain yield. Therefore, while improving grain yield, selection of parents based on number of characters having quantitative divergence is required that can be assessed by $\mathrm{D}^{2}$-statistics developed by Mahalanobis (1936).

\section{Materials and Methods}

The experimental material consisted of 70 bread wheat genotypes evaluated in randomized block design with three replications at Sagidividi Farm, Deprtment of Seed Science and Technology, JAU, Junagadh during rabi 2017-18 under normal sown irrigated conditions. Recommended agronomic practices were followed to raise good crop. The observations on ten metric traits viz., days to $50 \%$ flowering, days to maturity, grain filling period (days), plant height $(\mathrm{cm})$, number of productive tillers per plant, ear length $(\mathrm{cm})$, number of grains per main spike, grain weight per main spike (gm), grain yield per plant (gm), biological yield per plant (gm), harvest index (\%) and 1000 grain weight (gm) were recorded at appropriate crop growth stage. Five randomly selected competitive plants in each replication were recorded for all the traits under study except of days to heading, days to maturity and 1000 grain weight which were recorded on plot basis. The data were analyzed using WINDOSTAT version 9.1 software for computation of analysis of variance, genotypic coefficient of variation (GCV), phenotypic coefficient of variation (PCV), heritability in broad sense and clustering by Tocher's method.

\section{Results and Discussion}

In the present investigation, seventy diverse genotypes of bread wheat were studied to assess their yield and yield related attributing characters. The analysis of variance clearly indicated that there was highly significant variation among the genotypes for all the traits studied. This in turn indicated that there was sufficient variability in the material studied, which could be utilized in further breeding programme.

In the present study, $\mathrm{D}^{2}$ statistic estimated on 70 bread wheat genotypes for 12 characters showed that the generalized distance $\left(\sqrt{\mathrm{D}^{2}}\right)$ between two entries varied from 17.64 to 40.20 which was an indicator of diversity available in the material evaluated. On the basis of $\mathrm{D}^{2}$-values, five clusters were formed from 70 genotypes (Table 1). The clustering pattern of genotypes showed that the genotypes of different origins were clubbed in one cluster, whereas the genotypes belonging to same state or origin were grouped in different clusters indicating that the geographic distribution did not consider being the sole criterion of genetic diversity.

The cluster I and II contained eight and six genotypes from different origins, respectively. The cluster III and IV contained eight and fourty three genotypes each from different origins. On the other hand, cluster $\mathrm{V}$ is the smallest cluster among all clusters possessed only five genotypes. In general, intra cluster distances were lower than the inter-cluster distances (Table 2). Thus, the genotypes included within a cluster tended to less diverse from one another. 
Table. 1 Grouping of 70 genotypes of bread wheat in various clusters on the basis of $\mathrm{D}^{2}$ statistic

\begin{tabular}{|c|c|c|c|c|}
\hline \multirow{2}{*}{$\begin{array}{c}\text { Cluster } \\
\text { I }\end{array}$} & \multicolumn{2}{|c|}{$\begin{array}{c}\text { No. of } \\
\text { genotypes }\end{array}$} & \multirow{2}{*}{\begin{tabular}{|r|} 
Name of genotypes \\
NW 5054
\end{tabular}} & \multirow{2}{*}{$\begin{array}{c}\text { Place of origin } \\
\text { NDUAQT, Faizabad, Uttar Pradesh }\end{array}$} \\
\hline & 8 & 2 & & \\
\hline & & & HUW 675 & BHU, Varanasi, Uttar Pradesh \\
\hline & & 2 & AKAW 4899 & Akola, Maharashtra \\
\hline & & & NIAW 2349 & ARS, Niphad, Maharashtra \\
\hline & & 1 & UP 3000 & GBPUAT, Pantnagar, Uttaranchal \\
\hline & & 1 & RAJ 4350 & SKRAU, Durgapura, Rajasthan \\
\hline & & 1 & HD 2967 (C) & IARI, New Delhi \\
\hline & & 1 & PHSL 5 & IIWBR, Karnal, Haryana \\
\hline \multirow[t]{5}{*}{ II } & 6 & 2 & $\begin{array}{l}\text { PHSL } 10 \\
\text { DBW } 154\end{array}$ & $\begin{array}{l}\text { IIWBR, Karnal, Haryana } \\
\text { DWR, Karnal, Haryana }\end{array}$ \\
\hline & & 1 & NIAW 1994 & ARS, Niphad, Maharashtra \\
\hline & & 1 & GW 5014-560 & SDAU, Vijapur, Gujarat \\
\hline & & 1 & RAJ 4238 & SKRAU, Durgapura, Rajasthan \\
\hline & & 1 & PBW 681 & PAU, Ludhiana, Punjab \\
\hline \multirow[t]{3}{*}{ III } & 8 & 3 & DWAP 1530, KBRL 82-2, WS 1501 & IIWBR, Karnal, Haryana \\
\hline & & 3 & $\begin{array}{l}\text { UP } 2891 \\
\text { VL 1003, VL } 977\end{array}$ & $\begin{array}{l}\text { GBPUAT, Pantnagar, Uttaranchal } \\
\text { VPKAS, Almora, Uttaranchal }\end{array}$ \\
\hline & & 2 & AKAW 4900, AKAW 4924 & Akola, Maharashtra \\
\hline \multirow[t]{9}{*}{ IV } & 43 & 12 & $\begin{array}{l}\text { KBRL 81-1, KBRL 77-1, KBRL 77- } \\
\text { 2, KB 2013-05, DWAP 1531, LBPY } \\
\text { 2013-3, LBPY 2013-5, PHSL 11, } \\
\text { WS } 1503\end{array}$ & IIWBR, Karnal, Haryana \\
\hline & & & DBW 88, DBW 107, DBW 110 & DWR, Karnal, Haryana \\
\hline & & 5 & HS 592, HS 592, HS 547 & IARI, Shimla, Himachal Pradesh \\
\hline & & & HPW 360, HPW 368, HPW 411 & Palampur, Himachal Pradesh \\
\hline & & 5 & HI 1604, HI 1600, HI 1615 & IARI, RS, Indore, Madhya Pradesh \\
\hline & & & MP 3336, MP 3382 & JNKV, Jabalpur, M.P. \\
\hline & & 4 & $\begin{array}{l}\text { GW 2014-562, GW 451, GW 455, } \\
\text { GW } 461\end{array}$ & SDAU, Vijapur, Gujarat \\
\hline & & 4 & K 1204, K 0402 & CSAU\&T, Kanpur, Uttar Pradesh \\
\hline & & & HUW 666, HUW 677 & BHU, Varanasi, Uttar Pradesh \\
\hline
\end{tabular}




\begin{tabular}{|c|c|c|c|c|}
\hline & & 3 & HD 3132, HD 3133, HD 3146 & IARI, New Delhi \\
\hline & & 3 & UP 2864 & GBPUAT, Pantnagar, Uttaranchal \\
\hline & & & VL 967, VL 3004 & VPKAS, Almora, Uttaranchal \\
\hline & & 2 & NIAW 2844, NIAW 3033 & ARS, Niphad, Maharashtra \\
\hline & & 2 & RAJ 4393, RAJ 4444 & SKRAU, Durgapura, Rajasthan \\
\hline & & 2 & PBW 697, PBW 793 & PAU, Ludhiana, Punjab \\
\hline & & 1 & Sonalika (C) & IARI, Willington, Tamil Nadu \\
\hline V & 5 & 2 & K 1006, K 1317 & CSAU\&T, Kanpur \\
\hline & & 1 & KBRL 78-2 & IIWBR, Karnal, Haryana \\
\hline & & 1 & HS 547 & IARI, Shimla, Himachal Pradesh \\
\hline & & 1 & GW 2014-563 & SDAU, Vijapur, Gujarat \\
\hline
\end{tabular}

Table.2 Intra and inter cluster distances between five cluster

\begin{tabular}{|l|l|l|l|l|l|}
\hline $\begin{array}{c}\text { Cluster } \\
\text { No. }\end{array}$ & I. & II. & III. & IV. & V. \\
\hline I. & $\mathbf{1 8 . 9 1}$ & 18.48 & 29.45 & 23.56 & 40.20 \\
\hline II. & & $\mathbf{1 1 . 6 6}$ & 30.13 & 19.06 & 35.05 \\
\hline II. & & & $\mathbf{2 0 . 8 9}$ & 18.61 & 23.70 \\
\hline V. & & & & $\mathbf{1 9 . 4 4}$ & 17.64 \\
\hline V. & & & & & $\mathbf{1 1 . 2 8}$ \\
\hline
\end{tabular}

Table.3 Contribution of various traits towards total genetic divergence

\begin{tabular}{|c|l|c|c|}
\hline Sr. No & \multicolumn{1}{|c|}{ Characters } & Time ranked first & Contribution (\%) \\
\hline $\mathbf{1 .}$ & Days to 50\% flowering & 0 & 0.00 \\
\hline $\mathbf{2 .}$ & Days to maturity & 0 & 0.00 \\
\hline $\mathbf{3 .}$ & Grain filling period (days) & 2 & 0.08 \\
\hline $\mathbf{4 .}$ & Plant height (cm) & 15 & 0.62 \\
\hline $\mathbf{5 .}$ & Number of productive tillers per plant & 13 & 0.54 \\
\hline $\mathbf{6 .}$ & Ear length (cm) & 4 & 0.17 \\
\hline $\mathbf{7 .}$ & Number of grains per main spike & 134 & 5.55 \\
\hline $\mathbf{8 .}$ & Grain weight per main spike (g) & 740 & 26.50 \\
\hline $\mathbf{9 .}$ & Grain yield per plant (g) & 462 & 30.72 \\
\hline $\mathbf{1 0 .}$ & Biological yield per plant (g) & 15 & 19.13 \\
\hline $\mathbf{1 1 .}$ & Harvest index (\%) & 388 & 0.62 \\
\hline $\mathbf{1 2 .}$ & 1000 grain weight (g) & & 16.07 \\
\hline
\end{tabular}


Table.4 The cluster mean values of 12 characters in 5 clusters in 70 wheat genotypes

\begin{tabular}{|c|l|c|c|c|c|c|}
\hline $\begin{array}{c}\text { Sr. } \\
\text { No }\end{array}$ & \multicolumn{1}{|c|}{ Characters } & $\begin{array}{c}\text { Cluster } \\
\text { I }\end{array}$ & $\begin{array}{c}\text { Cluster } \\
\text { II }\end{array}$ & $\begin{array}{c}\text { Cluster } \\
\text { III }\end{array}$ & $\begin{array}{c}\text { Cluster } \\
\text { IV }\end{array}$ & $\begin{array}{c}\text { Cluster } \\
\text { V }\end{array}$ \\
\hline 1. & Days to 50\% flowering & 55.62 & 55.19 & 54.89 & 55.71 & 55.20 \\
\hline 2. & Days to maturity & 106.37 & 102.05 & 94.50 & 100.96 & 100.00 \\
\hline 3. & Grain filling period (days) & 36.83 & 39.96 & 35.33 & 35.75 & 36.13 \\
\hline 4. & Plant height (cm) & 66.38 & 63.92 & 58.41 & 61.19 & 68.09 \\
\hline 5. & Number of productive tillers per & 3.53 & 3.99 & 2.75 & 4.29 & 4.61 \\
\hline & plant & 8.03 & 7.79 & 7.47 & 7.96 & 7.85 \\
\hline 6. & Ear length (cm) & 27.94 & 23.65 & 21.48 & 40.64 & 27.18 \\
\hline 7. & Number of grains per main spike & 1.54 & 0.87 & 1.02 & 1.23 & 0.45 \\
\hline 8. & Grain weight per main spike (g) & 5.26 & 3.42 & 2.85 & 5.27 & 3.02 \\
\hline 9. & Grain yield per plant (g) & 17.88 & 11.76 & 11.15 & 22.70 & 11.32 \\
\hline 10. & Biological yield per plant (g) & 30.92 & 30.49 & 26.72 & 25.51 & 25.70 \\
\hline 11. & Harvest index (\%) & 55.31 & 33.26 & 48.98 & 30.32 & 16.30 \\
\hline 12. & 1000 grain weight (g) & & & & & \\
\hline
\end{tabular}

The intra-cluster distance was ranged from 11.28 (cluster V) to 20.89 (cluster III). High intra-cluster distance indicated about the wider genetic diversity among the genotypes which could be used in yield improvement of bread wheat. The maximum inter-cluster distance (D) was observed between cluster $\mathrm{I}$ and $\mathrm{V}$ $(\mathrm{D}=40.20)$ followed by that between cluster II and $\mathrm{V}(\mathrm{D}=35.05)$, while the closest proximity was noticed between cluster IV and $\mathrm{V}$ $(\mathrm{D}=17.64)$. The genotypes belonging to the clusters separated by high statistical distance could be used in hybridization programme for obtaining a wide spectrum of variation among the segregates or to exploit maximum level of hybrid vigour in bread wheat. In this context, genotypes from cluster I (NW 5054, HUW 675, AKAW 4899, NIAW 2349, UP 3000, RAJ 4350, HD 2967 (C), PHSL 5; cluster II (PHSL 10, DBW 154, NIAW 1994, GW 5014-560, RAJ 4238, PBW 681) and cluster V (K 1006, K 1317, KBRL 78-2, HS 547, GW 2014-563) should be selected as parents in hybridization programme.

A wide range of variation for several characters among multi-genotypic clusters was observed. However, the most important trait causing maximum genetic divergence was observed in grain yield per plant $(30.72 \%)$ and was responsible for differentiating the genotypes studied. Grain weight per main spike $(26.50 \%)$, biological yield per plant (19.13\%) and 1000 grain weight $(16.07 \%)$ were the next important traits contributed to total genetic divergence (Table 3). A considerable diversity of $92.42 \%$ was observed due to these four characters. Hence, selection for divergent parents based on these four characters would be useful for heterosis breeding in bread wheat. Nimbalkar et al., (2002); Dobariya et al., (2006) and Chapla et al., (2008) also reported the same results. Harvest index $(0.62 \%)$, plant height $(0.62 \%)$, number of productive tillers per plant $(0.54 \%)$, ear length $(0.17 \%)$, and grain filling period $(0.08 \%)$ contributed low (below 3\%) and days to $50 \%$ flowering and days to maturity contributed negligible (zero) towards the total genetic divergence. Low diversity for these traits in such diverse group of genotypes may also suggest high degree of consistency and moderate to low heritability of these traits.

By comparing the cluster means (Table 4), the cluster I differed from other clusters in respect of number ear length, grain weight per main spike, harvest index and 1000 grain weight, while cluster IV was the best for number of 
grains per main spike, grain yield per plant and biological yield per plant. The cluster III had desirable mean values for earliness, maturity, grain filling period and dwarfness i.e. days to $50 \%$ flowering, days to maturity, grain filling period and plant height. The cluster $\mathrm{V}$ was the best for number of productive tillers per plant, respectively. Selection of genotypes based on cluster mean for the better exploitation of genetic potential also reported by Hailegiorgis et al., (2011) and Desheva and Kyosev (2014).

In conclusion, it has been well established fact that more the genetically diverse parents used in hybridization programme, the greater will be the chances of obtaining high heterotic hybrids and broad spectrum variability in segregating generations. It has also been observed that the most productive hybrids may come from high yielding parents with a high genetic diversity. Therefore, in the present investigation, based upon high yielding genotypes and large intercluster distances, it is advisable to attempt crossing of the genotypes from cluster $\mathrm{V}$ with the genotypes of cluster I and II, respectively, which may lead to broad spectrum of favorable genetic variability for yield improvement in bread wheat.

\section{Acknowledgement}

With immense exhilaration I would like to express my deepest gratitude to the Department of Genetics and Plant Breeding, Junagadh Agricultural University, Junagadh, for scientific guidance and inspiration during the course of research work and perpetually assisted me with data acquisition and problem solution.

\section{References}

Anonymous. (2018). Director's Report of AICRP on Wheat and Barley 2016-17, Ed: Singh, G. R. ICAR-Indian Institute of Wheat and Barley Research, Karnal, Haryana, India. Report 87.

Arunachalam, V. (1981). Genetic distance in plant breeding. Indian J. Genet. \& Plant Breed., 41: 226-236.

Chapla, J. N.; Dobariya, K. L.; Khanpara, M. D.; Jivani, L. L. and Kachhadia, V. H. (2008). Genetic divergence in bread wheat (Triticum aestivum L.). Natl. J. Pl. Improv., 10(2): 97-102.

Desheva, G., and Kyosev, B. (2014). Genetic diversity assessment of common winter wheat (Triticum aestivum L.). Emir. Journal of Food Agriculture. 27(3): 283290.

Dobariya, K. L.; Ribadia, K. H.; Padhar, P. R. and Ponkia, H. P. (2006). Analysis of genetic divergence in some synthetic lines of bread wheat (Triticum aestivum L.). Adv. Pl. Sci., 19(2): 221-225.

Hailegiorgis, D., Mesfin, M. and Genet, T. (2011). Genetic divergence analysis on some bread wheat genotypes grown in Ethiopia. Journal of Central European Agriculture. 12(2): 344-352.

Mahalanobis, P. C. (1936). On the generalized distance in statistics. Proc. Nat. Inst. Sci., 2: 49-55.

Mary, S. S. and Gopalan, A. (2006). Dissection of genetic attributes yield traits of fodder cowpea in $\mathrm{F}_{3}$ and $\mathrm{F}_{4}$. J. Appl. Sci. Res., 2(10): 805-808.

Nimbalkar, C. A., Navale P. A. and Biradar, A. B. (2002). Generalized $D^{2}$ and genetic diversity in wheat. J. Maharashtra Agric. Univ., 27(1): 43-45.

\section{How to cite this article:}

Karthikeya Reddy, S.G.P., C.A. Babariya and Sapovadiya, M.H. 2019. Assessment of Genetic Diversity in Bread Wheat (Triticum aestivum L.) Genotypes. Int.J.Curr.Microbiol.App.Sci. 8(06): 1714-1719. doi: https://doi.org/10.20546/ijcmas.2019.806.204 